\title{
Multi-output current source with ripple cancellation by optimal magnetic components
}

\author{
Di Zhang, Donglai Zhang ${ }^{\mathrm{a}}$ and He Liu \\ Power Electronic \& Motion Control Research Center, Harbin Institute of Technology Shenzhen Graduate School, \\ Shenzhen 518055, China
}

\begin{abstract}
High integration, high power density has become the development trend of power supply. Computer, automobile and aviation often require multiple output power, in order to meet all kinds of load, and the filter of current type output for the power supply should be a larger challenge. The input voltage becomes wide and high, and each output is low voltage with large current. Compared to the non-isolation topologies, isolation topologies have better ability of step-up/down. In this paper, the two-stage converter structure is used, in which the forward stage is used to step down the amplitude of the input voltage, and the backward stage achieved precisely multiple current output with independent control. Also optimization and design of the transformer and output filters have been made clearly, to solve the problems of cross regulation, stability, and dynamic response in traditional structure. Finally, four-currentoutput prototype with $80-100 \mathrm{~V}$ input, $8 \mathrm{~A} / 10 \mathrm{~V}, 8 \mathrm{~A} / 10 \mathrm{~V}, 6 \mathrm{~A} / 20 \mathrm{~V}$, and $6 \mathrm{~A} / 20 \mathrm{~V}$ outputs is built, and the analysis is verified by the experimental results.
\end{abstract}

Keywords: multi-output; ripple cancellation; optimal design; current source.

\section{Introduction}

Multiple current output converters have been widely used in computer power supply, automotive electronics, LED driver, aerospace and other fields [1-5]. The main purpose of multiple output is to reduce the usage of the magnetic devices, and through the effective integration to share the same structure. According to different requirements, isolation type is quite suit for high voltage difference between input and output. The traditional structure of buck converter through certain adjustment, such as the tapped-inductor high step-down ratio method [6], transformer-less interleaved mode [7], can realize a wide range of high step-down ratio, however the design of the output filter or the whole structure is complex with high switch stress, which is difficult to achieve multiple output well and limit the feasibility of the scheme.

As the topology proposed in [8], a multi-output power supply is proposed in non-isolation mode, by effective integration, multiple buck structures share the single inductor. By load-dependent peakcurrent control technique, the sequence was able to simultaneously regulate the buck output voltage and store the charge in the inductor. Under various conditions, the topology can work in continuous conduction mode, and improve the cross-regulation with well controlled accuracy even under lightload condition as well. However, a whole consideration should be taken into account to make sure all

${ }^{a}$ Corresponding author : zhangdl@hitsz.edu.cn

(C) 2016. The authors - Published by Atlantis Press 
branches work under CCM, which is easily affected by many factors. At the same time for high voltage difference between the input and the output, the current stress for all switches device will be large, and the efficiency will be affected.

Compared to the non-isolated type topology, isolated topology has a better adaptability of wide voltage range. High frequency transformer can effectively realize step down the input voltage with different controlled switch devices. Commonly, fly back converter was often applied to design different kinds of auxiliary power, or applied to small power conditions [9-11]. Each output voltage was realized by matching the by turns ratio between the output voltage of main path, to make the final output voltage stability. Among all the branches, the high accuracy of voltage or the largest power branch was often chosen as the controlled object to realize closed loop control. However, under light load or load step for the main branch, the converter will lead to a large voltage fluctuation to other branch sharing the coupling transformer. Given to the transferred power to the secondary side, most current will be assigned to the branch with the smallest leakage inductance, therefore, by making suitable various configuration of inductance for different branches, which is proportional to square of the turns ratio, and greater than the leakage inductance can effectively the influence of various cross regulation [9].

The forward topology can also achieve multi-output ability, the topology in [12] all the filter inductor are coupled with the same proportion ratio as turns ratio, which will improve the utilization of the magnetic core, also effectively reduce the influence of cross regulation, but not eliminate completely. An improved multiple output forward converter was proposed in [13], as the influence of cross regulation, the main branch was controlled by the forward converter as a feedback, and other branches were controlled by additional switches in each path. In [14] multiple frequency power with sharing single transformer was used to improve the performance. As different frequencies power combined together, the power with different cut-off frequency was made through high-pass, band-pass and low-pass filter, to get the corresponding power components, so as to reduce the influence of cross regulation. But the design of the transformer and filter were quite flexible, which were not able to extend to current source converters.

To overcome the drawbacks of cross regulation and high input voltage, for multiple current source converter also need the output with little ripple, high dynamic response. To meet all the requirement, a two-stage isolated multi-output current source (TIMCS) converter is proposed in this paper. The twostage structure can be treated as the trade-off and improved solution of high input voltage, which includes the following advantages.

Two-stage converter can effectively realize a middle voltage bus. And by different turn ratio, all the branches can work as voltage-controlled current source (VCCS), which can make the output current independent, reducing the influence of cross regulation.

By using the ripple cancellation, each branch of the converter can be obtained high dynamic response with little magnetic components. Also the optimization design of the filter, small inductor and capacitor can be used to improve the power density.

The forward structure with feed-forward control can make the middle voltage bus change more slowly, which improve the whole performance of the converter.

The optimization of the transformer makes the whole power transfer by several small ones. Although the whole power can not change, each transformer core can be design for its own requirement, not determined by the window area.

Based on the ripple cancellation, the buck converter has been presented in [15], however, the design of the filter can be optimized further. And the optimization of magnetic components has been researched in [16], according to the method, the whole magnetic components can be chose more easily. In section II, the existent ripple cancellation topologies has been discussed first, then the proposed optimized voltage-controlled current source based on buck converter is deduces; in Section III, the small-signal model is built to analysis the control loop; in Section IV, the experimental results are presented to show the effectiveness and analysis of the whole converter; and the conclusion is given in Section V. 


\section{Derivation of the proposed TIMCS converter}

\subsection{The existent ripple-cancellation converter}

To guarantee the output with little voltage/current ripple, several researches have been made to improve the performance [17-18]. The traditional buck or boost topology was the basic circuit to fulfil the requirement of step up/down, however, they have several problems, such as the discontinuous input voltage for buck, and the right-half-plane zero problem for boost. To make the output voltage with little ripple, the ripple current cancellation circuit (RCCC) shown in Figure 1 was proposed in [15]. In RCCC, an additional transformer T, a branch inductor L2 and a branch capacitor were used to cancel the AC current part of the main branch of L1. However, for the voltage-controlled current source, several inherent deficiencies limit for multi-output current circuit.

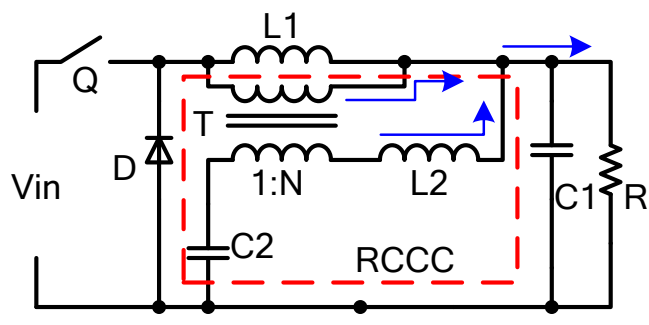

Figure 1. The ripple current cancellation circuit (RCCC) converter

1) The RCCC can realize the little current ripple with additional passive components. However the power density does not improve.

2) Transformer is used to reflect the voltage across L1 to a lower voltage, and the turn ratio, N, of the transformer, T, is determined by the inductors L1 and L2. The inductor L2 and capacitor C2 are both related to $\mathrm{N}$, which is quite flexible to make good consistency.

\subsection{The proposed voltage-controlled current source with ripple-cancellation}

For VCCS, to overcome the aforementioned disadvantage, another type of ripple cancellation structure shown in Figure 2 is used to get little current ripple with high power density, which can be efficient for multi-output converter. Compared to the traditional buck converter, using the RCCC concept, the circuit in Fig. 2 has no output capacitor for VCCS, and the main inductor L1 is coupled with the branch inductor L2 with low coupling coefficient. The additional DC blocking capacitor, C, will self bias up to the output voltage which is determined by the output current and load.

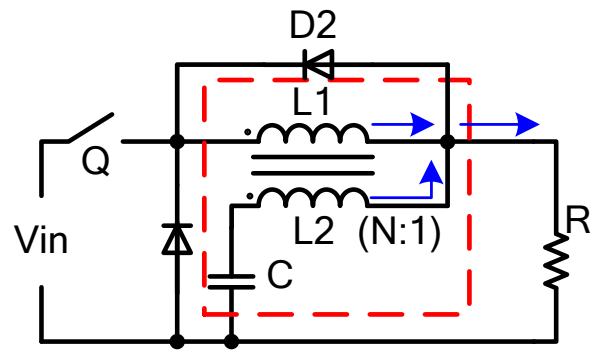

Figure 2. The ripple current cancellation circuit for VCCS

The output ripple current cancellation circuit topology works as shown in Figure 3. The current in the main branch inductor, L1, denoted as $I_{\mathrm{L} 1}$, and the current of the ripple-cancelled branch inductor, $\mathrm{L} 2$, denoted as $I_{\mathrm{L} 2}$. As it can be seen, when the switch is conducted, the output current $I_{\text {out }}$ mainly 
determined by DC component of $I_{\mathrm{L} 1}$, and the AC component of $I_{\mathrm{L} 1}$ is coupled to L2 judged by the dotted terminal, which will be transfer to the DC blocking capacitor.

When the switch turns off, $I_{\mathrm{L} 1}$ will go through L1 to the load without changing direction, and $I_{\text {out }}$ will flow through the diode to guarantee the continuous load current. And the energy of $C$ will be released to ripple-cancelled branch, through coupling inductance L2 to guarantee the final output current for dc ripple be small.

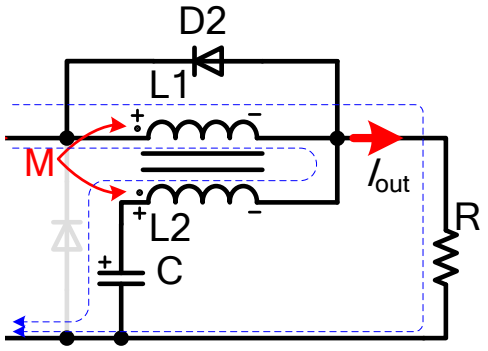

a) Turn-on state

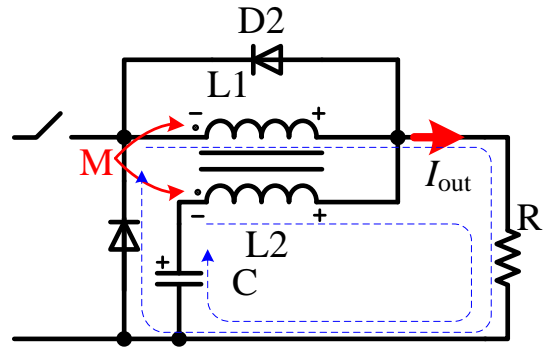

b) Turn-off state

Figure 3. The working mode for VCCS with ripple cancellation

The design philosophy of the parameter of L1, L2 and C should take several factors into account. First, the design for L1, after adding the ripple cancellation branch, L1 and L2 are coupled with the dotted terminal shown in Fig.2. The mutual inductor is denoted as M, and (L1-M) will stands for the equivalent decoupling inductor. It should guarantee the output current $I_{\text {out }}$ work in CCM mode. $I_{\mathrm{p}-\mathrm{p}}$ was denoted as the output peak-to-peak current, and then the minimum of (L1-M) should be:

$$
(L 1-M)_{\min }=\frac{\left(V_{\text {in }}-V_{\text {out }}\right)_{\max } T_{\text {on }}}{I_{\mathrm{p}-\mathrm{p}}}
$$

Where $V_{\text {in }}$ is the input voltage, and $V_{\text {out }}$ is the output voltage. $T_{\text {on }}=D^{*} T$, is the conduction time of the switch, $T$ is the controlling cycle, and $D$ is the duty cycle for the switch.

Then, the DC blocking capacitor, $\mathrm{C}$ should be the energy storage part, and the voltage of $\mathrm{C}$ will bias up to the output voltage. So the mean voltage, $V_{c}$, will be shown in equation (2), and the instantaneous value, $v_{\mathrm{c}}$, should be shown as equation (3). To guarantee efficient ripple cancellation of $\mathrm{L} 2$, the ripple voltage for $\mathrm{C}$ charging/discharging, denoted as $\Delta V_{\mathrm{cmax}}$ should smaller than the minimum of the final output voltage, shown in equation (4), which can determine the minimum capacitor C.

$$
\begin{gathered}
V_{\mathrm{c}}=V_{\text {out }} \\
v_{\mathrm{c}}=v_{\mathrm{L} 2}+v_{\text {out }} \\
\Delta V_{\text {cmax }} / 2<V_{\text {outmin }}
\end{gathered}
$$

Where $v_{\mathrm{L} 2}$ is the instantaneous voltage of $\mathrm{L} 2$.

Finally, using the result of $\mathrm{C}$ to calculate the real $\Delta V_{\mathrm{c}}$, which is shown in equation (5)

$$
\Delta V_{\mathrm{c}}=\frac{I_{\mathrm{p}-\mathrm{p}} T_{\text {off }}}{8 \mathrm{C}}
$$

According to equation (3) and assuming that the final output current with zero-ripple, then it should be:

$$
\left(L_{2}-M\right)=\frac{T_{\text {off }} \Delta V_{\mathrm{c}}}{I_{\mathrm{p}-\mathrm{p}}}
$$


Based on the equation (1)-(6), the parameter of (L1-M), C and (L2-M) can be designed. Commonly, the value of (L2-M) was quite small, which means L2 has the approximate value with M. For toroidal cores, the two coupling windings are made in separated mode, shown in Figure 4, with the coupling coefficient of 0.75 .

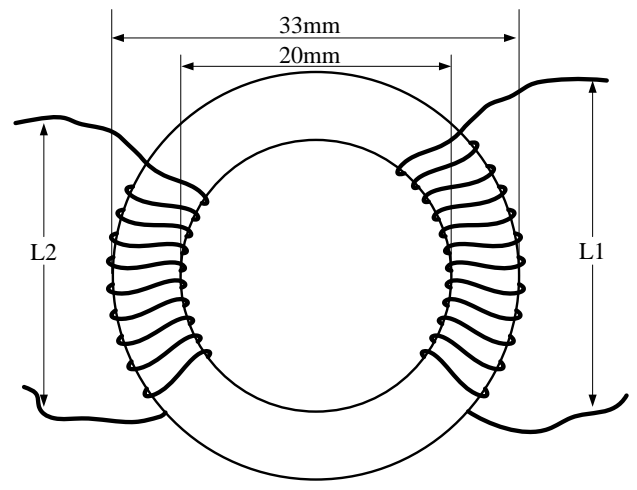

Figure 4. The winding of coupling inductor

\section{Small signal model of TIMCS converter}

The basic topology of the TIMCS converter is shown in Figure 5, which is made of the forward fullbridge converter with feed-forward control and the second stage multiple output VCCS. Full-bridge converter can with high frequency transformer, can facilitate the implementation of a multi-channel power output. At the same time, it can improve the utilization rate of energy and to optimize the use of magnetic materials, improve the overall efficiency. And the volume of a transformer is associated with a variety of factors, such as the number of multiple power supplies, the turns ratio, as well as the overall power level. It is difficult to make an optimization to balance all the requirements. As the number of multiple power supplies increased, the magnetic core will be decided by the window area, which will reduce the utilization rate of the magnetic core and the power density.

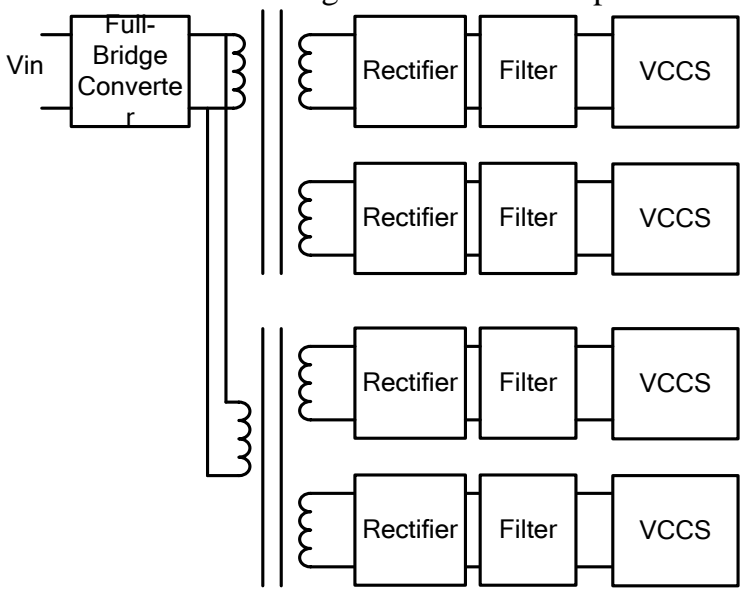

Figure 5. The basic topology of the proposed converter

As it can be seen in Figure 6, the switching frequency of the forward stage is $50 \mathrm{kHz}$, transformers are used as multiple-winding mode. It can realize the high frequency distribution, through the rectifier and filter, all channel for the VCCS can be treated as equivalent voltage source. The forward stage is controlled by UCC3895, which is used as a open-loop controller with feed-forward part. 


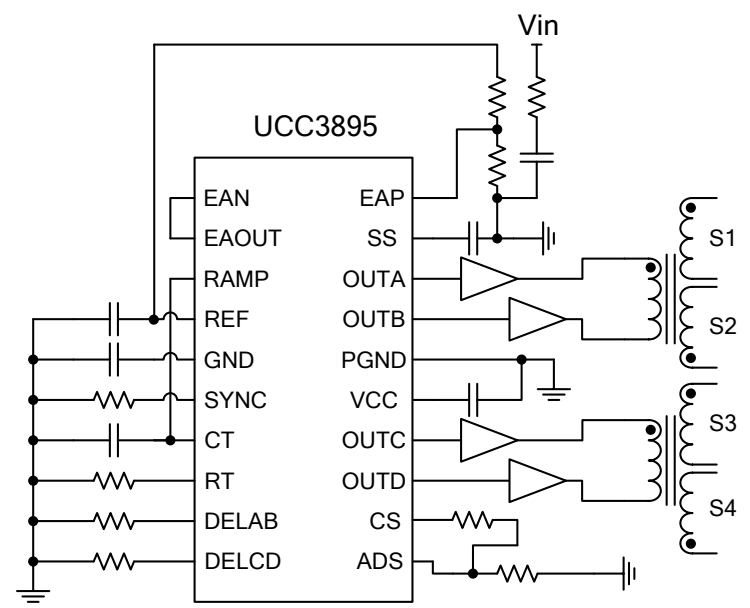

a) the basic circuit of UCC3895 controller

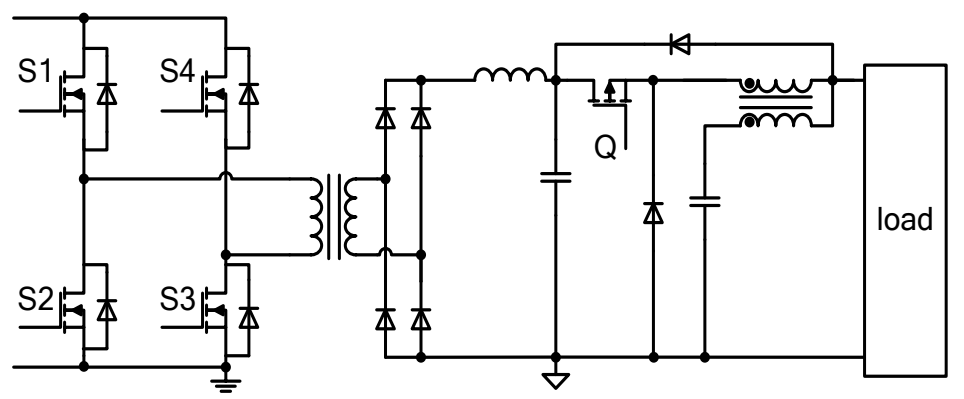

b) the diagram of one output circuit

Figure 6. The controller and circuit for the proposed topology

Because the forward stage is open loop, the small-signal analysis of the whole converter can be simplified to analyze the VCCS part. The equivalent circuit diagram of VCCS circuit is shown in Figure 7, according to the Kirchhoff's law, the different states for the switch Q are shown in Figure 8.

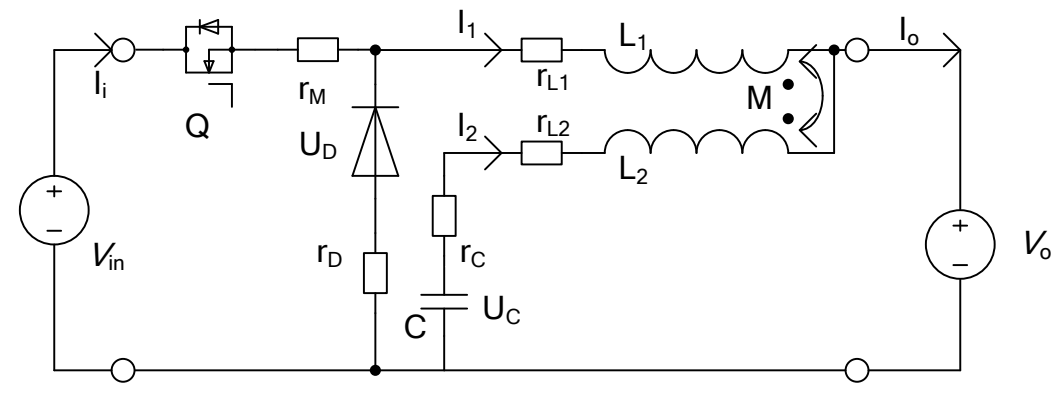

Figure 7. The equivalent circuit diagram of VCCS circuit 


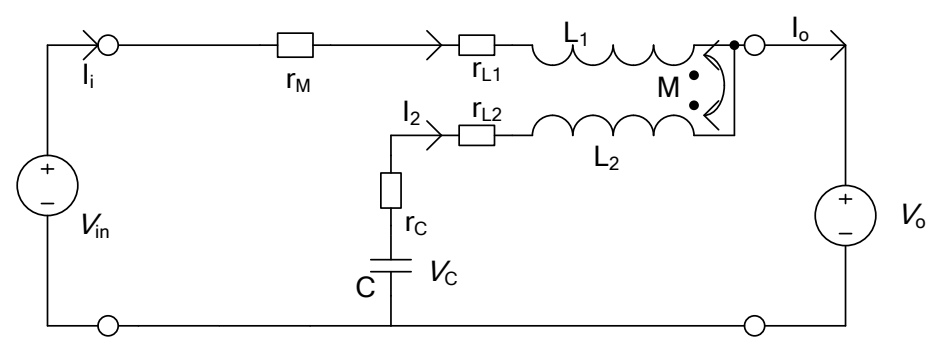

a) the equivalent circuit for the switch turns on
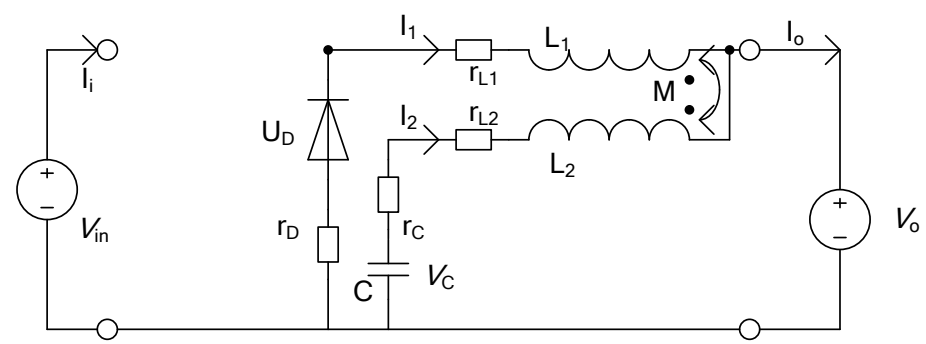

b) the equivalent circuit for the switch turns off

Figure 8. The equivalent circuit diagram for the VCCS circuit under different working modes

When the circuit working in turn-on mode and switch frequency is greater than the natural frequency of the converter, ignoring the effects of parasitic parameters, according to the state average method, it can get the following differential equations:

$$
\begin{gathered}
\mathrm{L}_{1} \frac{\mathrm{d} I_{\mathrm{L} 1}}{\mathrm{~d} t}+\mathrm{M} \frac{\mathrm{d} I_{\mathrm{L} 2}}{\mathrm{~d} t}=U_{\mathrm{i}}-U_{\mathrm{o}}-I_{\mathrm{L} 1}\left(\mathrm{r}_{\mathrm{M}}+\mathrm{r}_{\mathrm{L} 1}\right) \\
\mathrm{L}_{2} \frac{\mathrm{d} I_{\mathrm{L} 2}}{\mathrm{~d} t}+\mathrm{M} \frac{\mathrm{d} I_{\mathrm{L} 1}}{\mathrm{~d} t}=U_{\mathrm{C}}-U_{\mathrm{o}}-I_{\mathrm{L} 2}\left(\mathrm{r}_{\mathrm{C}}+\mathrm{r}_{\mathrm{L} 2}\right) \\
\mathrm{C} \frac{\mathrm{d} U_{\mathrm{C}}}{\mathrm{d} t}=-I_{\mathrm{L} 2} \\
I_{\mathrm{i}}=I_{\mathrm{L} 1} \\
I_{\mathrm{O}}=I_{\mathrm{L} 1}+I_{\mathrm{L} 2}
\end{gathered}
$$

When the circuit working in turn-off mode, according to Fig.8(b), it can get the following differential equations:

$$
\begin{gathered}
\mathrm{L}_{1} \frac{\mathrm{d} I_{\mathrm{L} 1}}{\mathrm{~d} t}+\mathrm{M} \frac{\mathrm{d} I_{\mathrm{L} 2}}{\mathrm{~d} t}=-U_{\mathrm{D}}-U_{\mathrm{o}}-I_{\mathrm{L} 1}\left(\mathrm{r}_{\mathrm{D}}+\mathrm{r}_{\mathrm{L} 1}\right) \\
\mathrm{L}_{2} \frac{\mathrm{d} I_{\mathrm{L} 2}}{\mathrm{~d} t}+\mathrm{M} \frac{\mathrm{d} I_{\mathrm{L} 1}}{\mathrm{~d} t}=U_{\mathrm{C}}-U_{\mathrm{o}}-I_{\mathrm{L} 2}\left(\mathrm{r}_{\mathrm{C}}+\mathrm{r}_{\mathrm{L} 2}\right) \\
\mathrm{C} \frac{\mathrm{d} U_{\mathrm{C}}}{\mathrm{d} t}=-I_{\mathrm{L} 2} \\
I_{\mathrm{i}}=0
\end{gathered}
$$




$$
I_{\mathrm{O}}=I_{\mathrm{L} 1}+I_{\mathrm{L} 2}
$$

According to the State-Space Averaging Method, denote the duty cycle as $\mathrm{D}$, and $\mathrm{D}^{\prime}=1-\mathrm{D}$, then the above equations can be available as:

$$
\begin{gathered}
\mathrm{L}_{1} \frac{\mathrm{d} I_{\mathrm{L} 1}}{\mathrm{~d} t}+\mathrm{M} \frac{\mathrm{d} I_{\mathrm{L} 2}}{\mathrm{~d} t}=D U_{\mathrm{i}}-D^{\prime} U_{\mathrm{D}}-U_{\mathrm{o}}-I_{\mathrm{L} 1}\left(D \mathrm{r}_{\mathrm{M}}+D^{\prime} \mathrm{r}_{\mathrm{D}}+\mathrm{r}_{\mathrm{L} 1}\right) \\
\mathrm{L}_{2} \frac{\mathrm{d} I_{\mathrm{L} 2}}{\mathrm{~d} t}+\mathrm{M} \frac{\mathrm{d} I_{\mathrm{L} 1}}{\mathrm{~d} t}=U_{\mathrm{C}}-U_{\mathrm{o}}-I_{\mathrm{L} 2}\left(\mathrm{r}_{\mathrm{C}}+\mathrm{r}_{\mathrm{L} 2}\right) \\
\mathrm{C} \frac{\mathrm{d} U_{\mathrm{C}}}{\mathrm{d} t}=-I_{\mathrm{L} 2} \\
I_{\mathrm{i}}=D I_{\mathrm{L} 1} \\
I_{\mathrm{O}}=I_{\mathrm{L} 1}+I_{\mathrm{L} 2}
\end{gathered}
$$

Decoupling the equations (17) and (18):

$$
\begin{array}{r}
\frac{\mathrm{d} I_{\mathrm{L} 1}}{\mathrm{~d} t}=\frac{\left[D U_{\mathrm{i}}-D^{\prime} U_{\mathrm{D}}-U_{\mathrm{o}}-I_{\mathrm{L} 1}\left(D \mathrm{r}_{\mathrm{M}}+D^{\prime} \mathrm{r}_{\mathrm{D}}+\mathrm{r}_{\mathrm{L} 1}\right)\right] \mathrm{L}_{2}-\left[U_{\mathrm{C}}-U_{\mathrm{o}}-I_{\mathrm{L} 2}\left(\mathrm{r}_{\mathrm{C}}+\mathrm{r}_{\mathrm{L} 2}\right)\right] \mathrm{M}}{\mathrm{L}_{1} \mathrm{~L}_{2}-\mathrm{M}^{2}} \\
\frac{\mathrm{d} I_{\mathrm{L} 2}}{\mathrm{~d} t}=\frac{\left[U_{\mathrm{C}}-U_{\mathrm{o}}-I_{\mathrm{L} 2}\left(\mathrm{r}_{\mathrm{C}}+\mathrm{r}_{\mathrm{L} 2}\right)\right] \mathrm{L}_{1}-\left[D U_{\mathrm{i}}-D^{\prime} U_{\mathrm{D}}-U_{\mathrm{o}}-I_{\mathrm{L} 1}\left(D \mathrm{r}_{\mathrm{M}}+D^{\prime} \mathrm{r}_{\mathrm{D}}+\mathrm{r}_{\mathrm{L} 1}\right)\right] \mathrm{M}}{\mathrm{L}_{1} \mathrm{~L}_{2}-\mathrm{M}^{2}}
\end{array}
$$

First set three intermediate variables to facilitate later expression and calculation:

$$
\begin{gathered}
\mathrm{R}_{1}=D_{\mathrm{M}}+D^{\prime} \mathrm{r}_{\mathrm{D}}+\mathrm{r}_{\mathrm{L} 1} \\
\mathrm{R}_{2}=\mathrm{r}_{\mathrm{C}}+\mathrm{r}_{\mathrm{L} 2} \\
U_{1}=U_{\mathrm{i}}+U_{\mathrm{D}}-I_{\mathrm{L} 1}\left(\mathrm{r}_{\mathrm{M}}-\mathrm{r}_{\mathrm{D}}\right)
\end{gathered}
$$

The system state space equations of small signal expressions have been shown as follows:

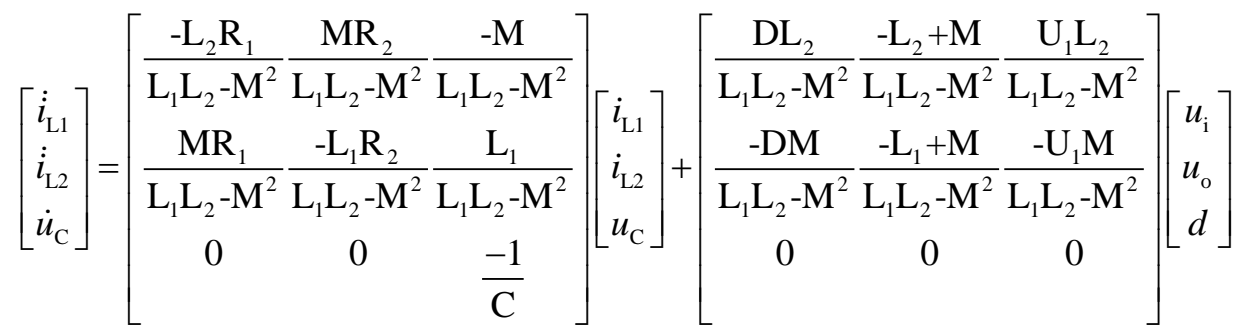

$$
\begin{aligned}
& {\left[\begin{array}{l}
i_{\mathrm{i}} \\
i_{\mathrm{o}}
\end{array}\right]=\left[\begin{array}{ccc}
D & 0 & 0 \\
1 & 1 & 0
\end{array}\right]\left[\begin{array}{l}
i_{\mathrm{L} 1} \\
i_{\mathrm{L} 2} \\
u_{\mathrm{C}}
\end{array}\right]+\left[\begin{array}{ccc}
0 & 0 & I_{\mathrm{L} 1} \\
0 & 0 & 0
\end{array}\right]\left[\begin{array}{l}
u_{\mathrm{i}} \\
u_{\mathrm{o}} \\
d
\end{array}\right]}
\end{aligned}
$$

The transfer function of duty cycle to output current control is: 


$$
\begin{gathered}
G_{c o-o}(s)=\frac{\mathrm{CU}_{1}\left(\mathrm{~L}_{2}-\mathrm{M}\right) s^{2}+\mathrm{CR}_{2} \mathrm{U}_{1} s+\mathrm{U}_{1}}{\Delta} \\
\Delta=\mathrm{C}\left(\mathrm{L}_{1} \mathrm{~L}_{2}-\mathrm{M}^{2}\right) s^{3}+\mathrm{C}\left(\mathrm{L}_{2} \mathrm{R}_{1}+\mathrm{L}_{1} \mathrm{R}_{2}\right) s^{2}+\left(\mathrm{L}_{1}+\mathrm{CR}_{2} \mathrm{R}_{1}\right) s+\mathrm{R}_{1}
\end{gathered}
$$

And according to the transfer function equation, the compensation network can be used to fulfill the close loop control, the loop gain bode plots are shown in Figure 9. And the dotted line is $\mathrm{G}_{\text {co-o- } \mathrm{L}}(\mathrm{s})$ before compensation, the solid line is $\mathrm{Lv}(\mathrm{s})$ after compensation. And phase angle margin is 58 degree, with the cross-over frequency of $2.52 \mathrm{kHz}$.

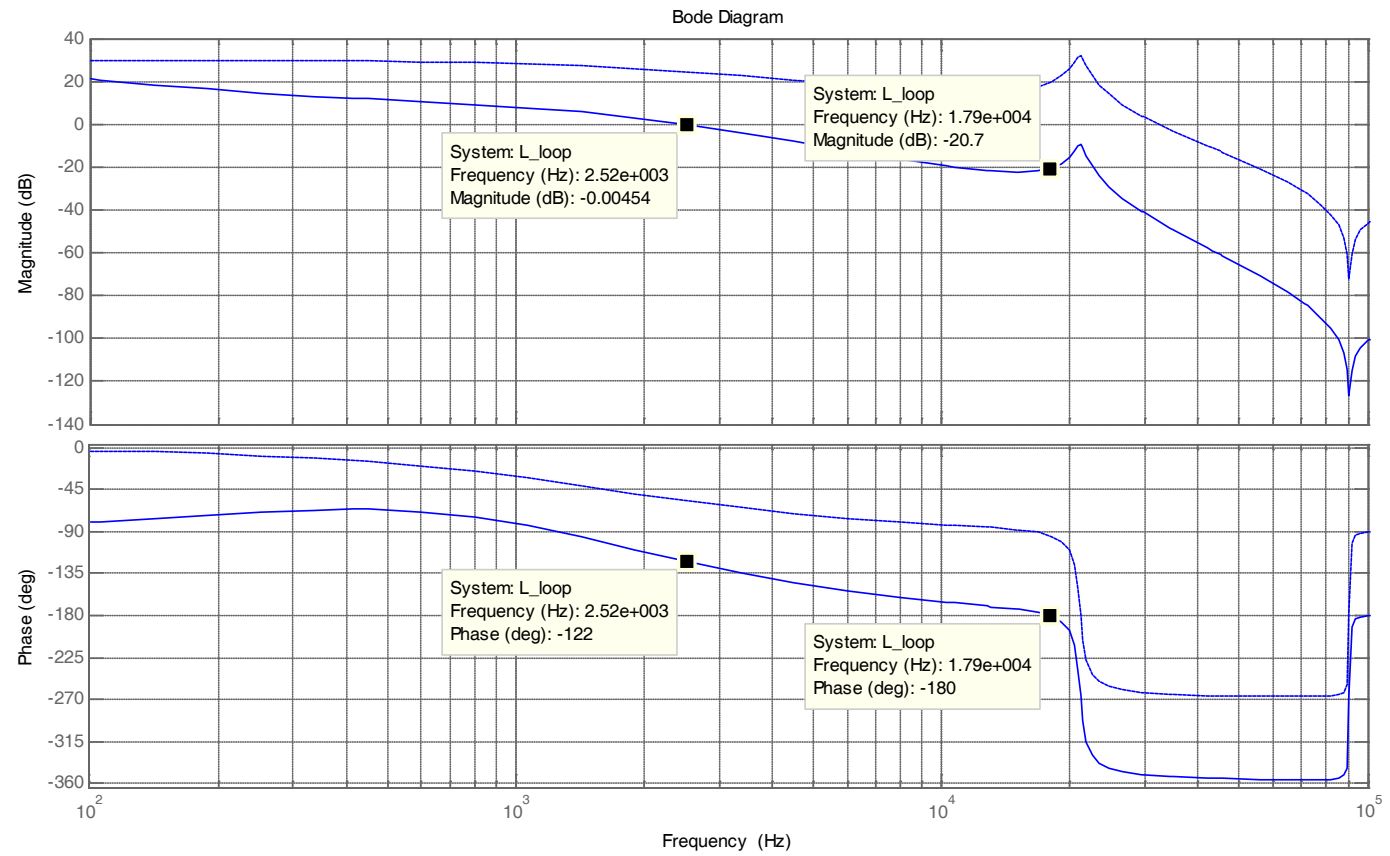

Figure 9. The closed loop gain bode figure

\section{Experiment results of TIMCS converter}

According to the analysis of the VCCS converter, a four-output prototype converter is build with $8 \mathrm{~A} / 10 \mathrm{~V}, 8 \mathrm{~A} / 10 \mathrm{~V}, 6 \mathrm{~A} / 20 \mathrm{~V}$, and $6 \mathrm{~A} / 20 \mathrm{~V}$. By applying the ripple cancellation method, the calculated parameter of the filter of each VCCS circuit has been shown in Table 1.

Table 1. The parameters of four-output filters

\begin{tabular}{|c|c|c|c|c|c|}
\hline No. & Current & L1(uH) & L2(uH) & Coupling coefficient & C(uF) \\
\hline 1 & $6 \mathrm{~A}$ & 199 & 112 & 0.743 & 2.2 \\
\hline 2 & $8 \mathrm{~A}$ & 100 & 60 & 0.752 & 2.2 \\
\hline 3 & $6 \mathrm{~A}$ & 202 & 110 & 0.736 & 2.2 \\
\hline 4 & $8 \mathrm{~A}$ & 103 & 59 & 0.748 & 2.2 \\
\hline
\end{tabular}

Because the four outputs can be divided into two kind, which are $6 \mathrm{~A} / 20 \mathrm{~V}$ and $8 \mathrm{~A} / 10 \mathrm{~V}$, the transformer has been designed as two independent toroid cores instead of one. Although the calculated 
window area is same, the window utilization rate of the cores are different. When only one core is used, the turn ratio of four outputs should be proportional to the primary side, so they cannot be optimized with each output. But changing one core into more smaller ones, and each turn ratio can be designed with own primary side. As a result, the magnetic core utilization can be improved. By the ripple cancellation, the output of 6A/20V and 8A/10V are shown in Figure 10.

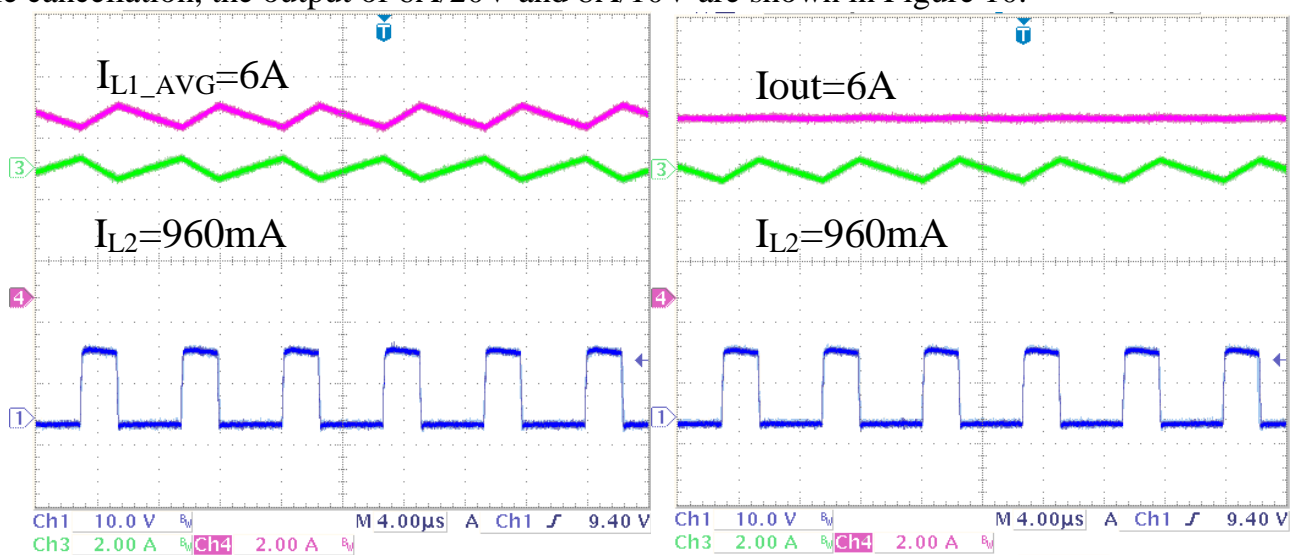

(a) $6 \mathrm{~A} / 20 \mathrm{~V}$ output current with little ripple

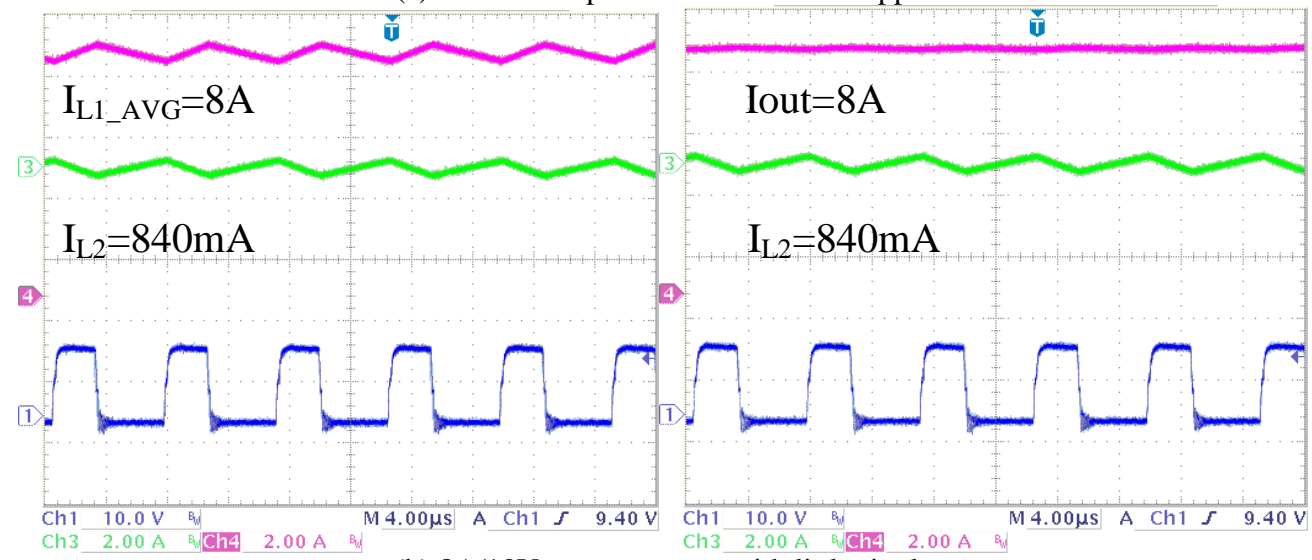

(b) $8 \mathrm{~A} / 10 \mathrm{~V}$ output current with little ripple

Figure 10. The output current with little ripple of $6 \mathrm{~A} / 20 \mathrm{~V}$ and $8 \mathrm{~A} / 10 \mathrm{~V}$

According to the experimental results, it can be seen that the ripple cancellation method can improve the whole output ripple, and all the filter inductor have smaller parameter comparing to the traditional buck converter. And the basic load switching experiment can show the dynamic performance of the TIMSC. Over the Figure 11, it can be seen that the accommodation time is around $1 \mathrm{~ms}$, and the overshoot can be kept within 25\%. The basic model of the TIMSC is shown in Figure 12. 

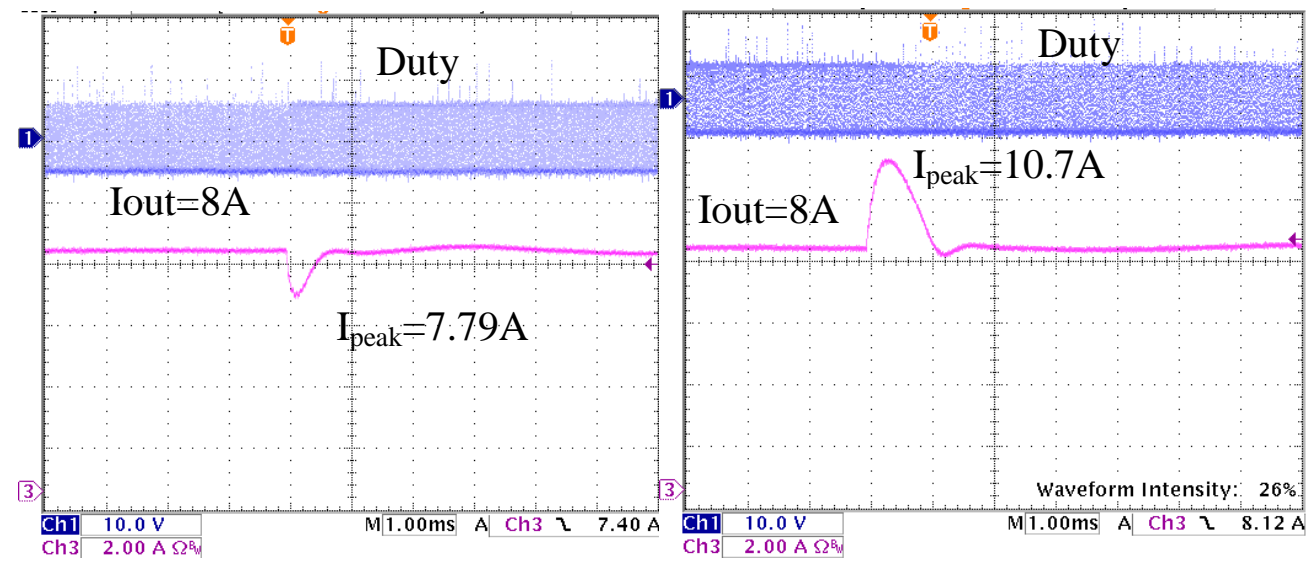

Figure 11. The output current for load switching experiment

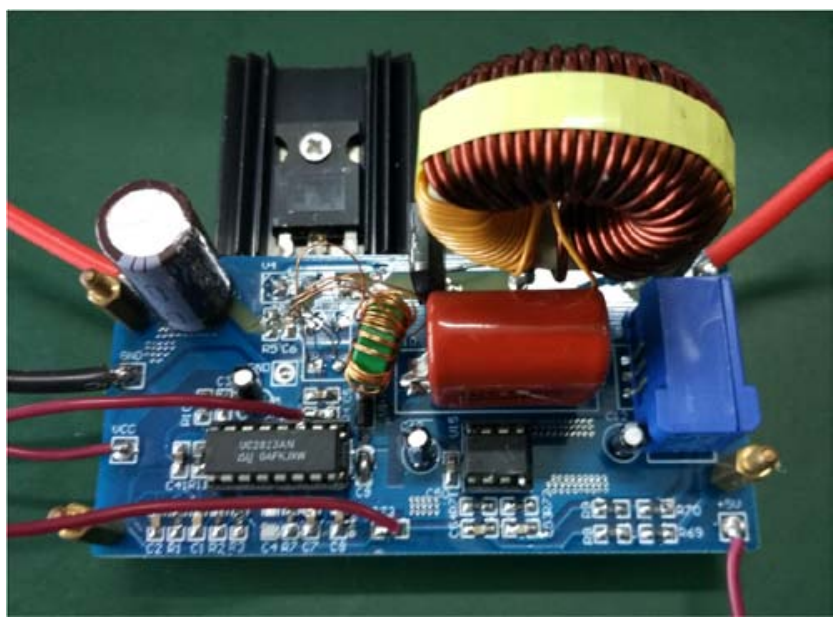

Figure 12. The basic model of TIMSC.

\section{Conclusion}

The multiple-output converter can be widely used in the fields of computer power supply, electric propulsion, and other applications. In this paper, for overcoming of disadvantages of the traditional multiple power supplies, a two-stage converter with current ripple cancellation topology has been proposed to improve the whole power density. By using ripple cancellation, the current ripple can be controlled within $5 \%$, and because this method, all the filter components can be quite small, which can improve the whole dynamic response. Also the whole principle of calculation method for ripple cancellation has been introduced. As the forward stage, a feed-forward control with open loop has been used to change the adaptability well.

\section{Acknowledgements}

This work was supported by the Basic Research Project from State Administration of Science, Technology and Industry for National Defence, PRC (Grant No.: JSZL2015603B004) and the Shenzhen Science and Technology Plan Project (Grant No.: JSGG20150529114007828 and JCYJ20140417172417127) 


\section{References}

1. nce. Intertec international, INC, 357-365(1995).

2. Chalermyanont K, Sangampai P, Prasertsit A, et al. High frequency transformer designs for improving cross regulation in multiple-output flyback converters. PEDS'07, 53-56(2007).

3. Maksimovic D, Erickson R W, Griesbach C. Modeling of cross-regulation in converters containing coupled inductors. IEEE Trans. on Power Electronics, 15, 4, 607-615(2000).

4. Kaushik L K, Pathak M K. An improved multiple output forward converter topology. 2010 Joint International Conf. on Power Electronics, Drives and Energy Systems (PEDES) \& 2010 Power India, 1-6(2010).

5. Benfeng Z, Huafeng L, Sunan L. Multi-channel adjustable DC power supply with single transformer based on spectral separation. Journal of Electrical Engineering, 65, 1, 50-54(2014).

6. Schutten M J, Steigerwald R LXu W, Li Y, Gong X, et al. A dual-mode single-inductor dualoutput switching converter with small ripple. IEEE Trans. on Power Electronics, 25,7, 614623(2010).

7. Zhang $\mathrm{J}, \mathrm{Xu} \mathrm{L}, \mathrm{Wu} \mathrm{X}$, et al. A precise passive current balancing method for multioutput LED drivers. IEEE Trans. on Power Electronics, 26, 8, 2149-2159(2011).

8. Simon M, Murken M, Augustin C, et al. Multi-Port Converter with bidirectional energy flow for automotive energy net applications. EPE'14-ECCE Europe, 1-10(2014).

9. Weinstein J, Huerta S C, Zhao Z, et al. Optimized phase positioning for minimizing input filter requirements in single-input multiple-output DC-DC switch-mode power supplies. APEC, 455459(2014).

10. Pinero L R, Hill G M, Aulisio M, et al. Status of a Power Processor for the Prometheus-1 Electric Propulsion System. AIAA/ASME/SAE/ASEE Joint Propulsion Conference \& Exhibit(2006).

11. Yao K, Ye M, Xu M, et al. Tapped-inductor buck converter for high-step-down DC-DC conversion. IEEE Trans. on Power Electronics, 20, 4, 775-780(2005).

12. Pan C, Chuang C, Chu C. A Novel Transformer-less Interleaved High Step-down Conversion Ratio DC-DC Converter with Low Switch Voltage Stress. IEEE Trans. on Industrial Electronics, 61, 10, 5290-5299(2014).

13. Huang M H, Chen K H. Single-inductor multi-output (SIMO) DC-DC converters with high lightload efficiency and minimized cross-regulation for portable devices. IEEE Journal of Solid-State Circuits, 44, 4, 1099-1111(2009).

14. Ji C, Smith Jr M, Smedley K M, et al. Cross regulation in flyback converters: analytic model and solution. IEEE Trans. on Power Electronics, 16, 2, 231-239(2001).

15. Marrero J. Improving cross regulation of multiple output flyback converters. Proceedings of the international power conversion confere, Sabaté J A. Ripple current cancellation circuit. APEC'03. Eighteenth Annual IEEE. 1, 464-470(2003).

16. Gu W J, Liu R. A study of volume and weight vs. frequency for high-frequency transformers. PESC'93 Record, 24th Annual IEEE, 1123-1129(1993).

17. Balog R S, Krein P T. Coupled-inductor filter: A basic filter building block. IEEE Trans on Power Electronics, 28, 1, 537-546(2013).

18. Gu Y, Zhang D, Zhao Z. Input/Output Current Ripple Cancellation and RHP Zero Elimination inBoost Converter using Integrated Magnetic Technique. IEEE Trans. On Power Electronics, 30, 2, 747-756 (2015). 